\title{
COMPLEX SURVEY QUESTIONS AND THE IMPACT OF ENUMERATION PROCEDURES:
}

\section{CENSUS/AMERICAN COMMUNITY SURVEY DISABILITY QUESTIONS}

\author{
by
}

\author{
Andrew J. Houtenville * \\ New Editions Consulting, Inc. \\ William A. Erickson * \\ Cornell University \\ and
Melissa J. Bjelland *
Cornell University

CES 09-10

April, 2009

The research program of the Center for Economic Studies (CES) produces a wide range of economic analyses to improve the statistical programs of the U.S. Census Bureau. Many of these analyses take the form of CES research papers. The papers have not undergone the review accorded Census Bureau publications and no endorsement should be inferred. Any opinions and conclusions expressed herein are those of the author(s) and do not necessarily represent the views of the U.S. Census Bureau. All results have been reviewed to ensure that no confidential information is disclosed. Republication in whole or part must be cleared with the authors.

To obtain information about the series, see www.ces.census.gov or contact Cheryl Grim, Editor, Discussion Papers, U.S. Census Bureau, Center for Economic Studies 2K130B, 4600 Silver Hill Road, Washington, DC 20233, Cheryl.Ann.Grim@census.gov. 


\begin{abstract}
This paper explores challenges relating to the identification of the population with disabilities, focusing on Census Bureau efforts using the 2000 Decennial Census Long-Form (Census 2000) and 2000-2005 American Community Survey (ACS). In particular, the analyses explore the impact of survey methods on responses to the work limitation (i.e., employment disability) question in these two Census products. Building on the research of Stern (2003) and Stern and Brault (2005), we look for further evidence of misreporting of an employment disability by specific sub-populations using the participation in the Supplemental Security Income program as an exogenous employment disability status indicator along with a subset of ACS disability questions. We expand upon these earlier studies by examining both false-positive and falsenegative reports of employment disability by implementing logit estimations to examine the role of respondent/enumerator error on the accuracy of the employment disability response. In this manner, we enhance our understanding of Census 2000 and ACS responses to employment disability questions through an exploration of the role of enumeration procedures in two types of misclassifications, as well as by evaluating existing data and estimates to uncover characteristics that might make an individual more likely to misreport an employment disability.
\end{abstract}

* The contents of this paper do not necessarily represent the policy of the Department of Education, and you should not assume endorsement by the Federal Government (Edgar, 75.620 (b)). The research in this paper was conducted while the authors were Special Sworn Status researchers of the U.S. Census Bureau at the New York Census Research Data Center at Cornell University. Any opinions and conclusions expressed herein are those of the author(s) and do not necessarily represent the views of the U.S. Census Bureau. All results have been reviewed to ensure that no confidential information is disclosed. Support for this research at the Ithaca RDC from NSF (ITR-0427889) is also gratefully acknowledged. This project was in part funded by the U.S. Department of Education, National Institute on Disability and Rehabilitation Research (NIDRR, Award No. H133G020117). We thank Lisa Dragoset and Pinky Chandra, the Cornell Census RDC Administrators, and all their Census Bureau colleagues who have helped this project along, especially Edward J. Welniak, Jr., Brian P. Holly, and Arnold P. Reznek. 


\section{Introduction}

This paper explores challenges relating to the identification of the population with disabilities, focusing on Census Bureau efforts using the 2000 Decennial Census Long-Form (Census 2000) and 2000-2005 American Community Survey (ACS). In particular, the analyses explore the impact of survey methods on responses to the work limitation (i.e., employment disability) question in these two Census products. Building on the research of Stern (2003) and Stern and Brault (2005), we look for further evidence of misreporting of an employment disability by specific sub-populations using the participation in the Supplemental Security Income program as an exogenous employment disability status indicator along with a subset of ACS disability questions. We expand upon these earlier studies by examining both false-positive and false-negative reports of employment disability by implementing logit estimations to examine the role of respondent/enumerator error on the accuracy of the employment disability response. In this manner, we enhance our understanding of Census 2000 and ACS responses to employment disability questions through an exploration of the role of enumeration procedures in two types of misclassifications, as well as by evaluating existing data and estimates to uncover characteristics that might make an individual more likely to misreport an employment disability.

\section{Background}

\section{A. Complexity of Measuring Disability}

Accurate identification of demographic subpopulations is imperative in order to impart knowledge to federal and state agencies regarding the most appropriate manner to allocate limited resources that can advance the well-being of disadvantaged groups. However, unlike age and gender, which are for the most part readily discernable individual attributes, disability is usually defined as a complex interaction between a person's health condition, personal characteristics, and the social and physical environment.

The two prominent frameworks of disability are the World Health Organization's (WHO, 2001) International Classification of Functioning, Disability and Health (ICF) and the disability model developed by Saad Nagi $\left(1965,1976\right.$, and 1979). ${ }^{1}$ Both of these conceptual models recognize disability as a dynamic process that involves the interaction of a person's health condition and personal characteristics with the physical and social environments. The Appendix provides a description of the ICF, which is additionally detailed in Figure 1.

In the Nagi Framework, depicted in Figure 2, disability results from a sequential progression of states. Pathology refers to the interruption or interference of normal bodily processes or structures at the cell or tissue level (e.g., multiple scars on the myelin sheaths of nerve cells are indicative of multiple sclerosis, or MS). Impairment refers to the loss of mental, emotional, physiological, or anatomical structure or function at the organ and person level (e.g., for MS, a change in sensation in the legs). Functional limitation refers to a limitation in performance of activities consistent with the function of the person (e.g., limitation in basic mobility). Disability refers to the inability or limitation in performing socially-defined roles and tasks expected of individuals within a social and physical environment (e.g., limitation in ability

\footnotetext{
${ }^{1}$ A detailed comparison of these two approaches is available in Jette and Badley (2000).
} 
to go outside the home and shop.) Another example of this is the ability to participate in the labor force, known as a work disability. ${ }^{2}$

Subtleties relating to the interpretation of disability have resulted in its myriad definitions. In a review of 67 federal statutes, the Interagency Committee on Disability Research found that 35 have self-contained definitions of disability, 26 use definitions from another statute, and six use definitions in more than one statute (CESSI, 2003). Mashaw and Reno (1996) document more than 20 definitions of disability used for the purposes of entitlement to public or private income transfers, government services, or statistical analysis. They argue that the appropriateness of any definition of disability depends on the purpose for which it is used.

While the meaning of disability varies across agencies, federal and state programs targeted at people who experience employment disabilities must rely upon shared data to assist them in identifying covered populations or to screen for people at risk to experience disabilityrelated events. These sources of information may produce disparate estimates with distinct policy implications. For example, work limitations may lead to eligibility for programs that provide earnings-replacement compensation, income support, or return-to-work training and services, including educational stipends (i.e., Social Security Disability Insurance (SSDI) and Supplemental Security Income (SSI), the state/federal vocational rehabilitation program, or a state worker's compensation claim). However, as Banks, Kapteyn, Smith, and van Soest (2005) discovered, the phrasing of work limitation questions in U.S. federal surveys can affect the determination of the share of people with a disability in the general population, with prevalence rates ranging from 18.0 percent in the National Health Interview Survey to 24.6 percent in the Current Population Survey.

Public-use surveys fill knowledge gaps between decennial censuses, but have their own limitations. The sample of respondents may not be representative of the underlying population, researchers are restricted from performing analyses using finer cuts of the data (i.e., low levels of geography or certain demographic characteristics), and estimates are sensitive to the phrasing or context of question items. The decennial censuses of the U.S. population target all people residing in America, with one in six housing units receiving the detailed Long-Form questionnaire. Thus, every ten years, the Census Bureau carefully designs questions to reveal population trends, inform local and national programs regarding the well-being of Americans, and evaluate the strength of the economy. This wealth of data forms a base from which projections regarding the anticipated growth of the nation are made.

\section{B. Census 2000 Concerns}

The disability items contained on the Census 2000 Long-Form questionnaire were intended to serve a variety of purposes, including: (i) informing the distribution of funds to develop programs for people with disabilities and the elderly under the Rehabilitation Act; (ii) providing data to ensure that comparable public transportation services are available for all segments of the population in accordance with the Americans with Disabilities Act (ADA); (iii) supporting federal grant awards under the Older Americans Act, based on the number of elderly people with physical and mental disabilities; (iv) determining the assignment of funds for masstransit systems to provide accessible facilities under the Federal Transit Act; (v) informing the

\footnotetext{
${ }^{2}$ Note that pathologies do not necessarily lead to impairment; impairments do not necessarily lead to functional limitation; and functional limitations do not necessarily lead to disability. Personal and environmental factors influence the movement between categories.
} 
distribution of funds for housing for people with disabilities under the Housing and Urban Development Act; (vi) determining the allocation of funds by states and local areas for employment and job training programs for veterans under the Job Training Partnership Act; and (vii) educating state and county agencies regarding anticipated eligible recipiency under the Medicare and Medicaid programs (Census, 2000). ${ }^{3}$ For these reasons, the Census 2000 LongForm was designed to identify six classifications of disability within the population: sensory, physical, mental, self-care, go-outside-home, and employment disability (i.e., work limitation). Figure 3 contains these questions as they appeared on the Census 2000 mail-back questionnaire, which are identical to the set of questions used in the 2000-2002 ACS. ${ }^{4}$

As initial results were derived from the Census 2000, concern arose about the length and complexity of the questions. In particular, the phrasing of question 17, which placed great distance between its stem and the employment disability question (17d), may have compromised the integrity of population estimates. Subsequent analysis of the Census 2000 data by Stern (2003) suggested that substantial respondent or enumerator error existed. According to Stern (2003), the employment-disability prevalence rate is significantly higher in the enumerated sample (17.7 percent) than in the mail-back sample (10.9 percent). Differences between the two samples are expected, because non-response to the mail-back form may be correlated with disability or other related characteristics. However, Stern (2003) reports only minor differences between the two samples in the sensory, mental, physical, and self-care disability rates. In addition, the employment-disability prevalence rate in the 2000 ACS mail-back sample was the same in the Census 2000 mail-back sample (both 10.9 percent), but the employment disability rate in the 2000 ACS enumerated sample was substantially lower (7 percent) than the rate in the Census 2000 enumerated sample (17.7 percent). This suggests that differences in the enumeration processes of the Census 2000 and 2000 ACS led to a substantial difference in disability rates, specifically the employment disability prevalence rates. Similar, but less disparate statistics are found when comparing the go-outside-home disability across these data sources.

Furthermore, an inspection of employment rates suggests the measurement error is systematically related to employment. According to Stern (2003), the employment rates of working-age people (ages 21-64) with employment disabilities were 75.0 percent in the enumerated sample and 54.8 percent in the mail-back sample. These differences are not apparent in the tabulations of the employment rate for those with sensory, physical, mental, and self-care disabilities in the Census or the ACS.

In short, these patterns suggest that persons who were enumerated in the 2000 Census were more likely to answer whether they went to work rather than whether they had difficulty going to work. One possible explanation for these patterns is that the Census 2000 Long-Form enumeration version (the go-outside-home and employment disability stem of question 17) was separated from sub-questions $17 \mathrm{a}$ and $17 \mathrm{~b}$ by a column break for persons other than the primary respondent (Person 1). Overall, Stern (2003) suggests that complexity and length of the six questions, enumeration procedures and the translation of the mail-back Long-Form into a format for enumerators may have played a role in the differences that exist in the estimates (both within and across data sources). Overall, Stern (2003) concludes, “... disability rates are sensitive to relatively minor differences both within surveys across mode and across two surveys.” The

\footnotetext{
${ }^{3}$ For specific citations of these statutes go to www.census.gov/pub/dmd/www/pdf/09h_di.pdf.

${ }^{4}$ See Houtenville and Erickson (2005) for more information on disability-related statistics in the Census 2000.
} 
unfortunate phrasing and the resulting misinterpretation of the subset of disability-related items caused the Census 2000 to fail to comprehensively capture the population with disabilities.

\section{Changes to the ACS Disability Questions}

Since the ACS continued to use the disability items from the Census 2000 in its questionnaires through 2002, it seemed likely that the trend of over-reporting would continue in those years. In response to this potential respondent/enumerator error, the Census Bureau made a seemingly minor change to the 2003 ACS questionnaire. Figure 3 contains the 2003 ACS questions from the paper version. The stem to question 17 was repeated before the go-outsidehome and employment disability questions, and the age skip pattern did not appear in the questions.

Stern and Brault (2005) confirm the beneficial impact of this decision by comparing the 2002 and 2003 ACS disability estimates. They show that the employment disability prevalence rate among persons ages 16-64 in the ACS mail-back sample declined from 8.7 percent in 2002 to 6.7 percent in 2003, which converges with the estimate from the enumerated sample -6.2 percent in 2003. Importantly, differences between the mail-back and enumerated samples in the sensory, physical, mental, and self-care disability rates remained relatively constant between 2002 and 2003. Stern and Brault (2005) state that "[t]he evidence presented suggests that it is not possible to discern which portion, if any, of the difference between 2002 and 2003 disability estimates can be attributed to actual change in the number or percentage of people with disabilities. As a result, the Census Bureau will not present any time-series data showing estimates from 2002 and earlier with data from 2003 and later for the affected items.”

Taken together, the loss of confidence in Census 2000 and 2000-2002 ACS estimates represents a significant reduction in information regarding people with disabilities. For instance, a majority of the Census 2000 Summary File information on disability, poverty, and educational attainment solely utilize an overall disability measure (the union of the six disability categories) instead of being separately presented by type of disability. Due to the questionable nature of two of the six indicators used to construct the aggregate variable, however, even these statistics may not accurately reflect the population with disabilities.

\section{Methodology}

In order to enhance the quality of the existing Census 2000 and ACS data and responses to employment disability questions, we begin by presenting a series of tables containing descriptive statistics from these data sources. A reduction in prevalence rates over the years may be due to increased false-negatives, decreased false-positives, or reduced true-positives. Investigating false-positives and false-negatives requires information about "true" disability status. The Census 2000 Long-Form and the ACS have information on employment disability from two sources: receipt of SSI among low income working-age individuals and the employment disability question. Working-age individuals receiving SSI should report an employment disability, which is in part the basis for receipt of SSI. Using SSI information, we can acquire a sense of the degree of false-negatives among a certain population. SSI information is not by itself useful for false-positives. The estimates reviewed in tabular form partition respondent samples by mode of data collection (i.e., mail-back or enumerated) and by participation in the Supplemental Security Income program. 
A primary goal (Goal 6.1) of the Center for Disease Control's Healthy People 2010 directly addresses the importance of having a common set of questions that identify people with disabilities included in the core of all relevant Healthy People 2010 surveillance instruments (U.S. Department of Health and Human Services, 2000). Recently, the set of six disability indicators contained on the 2008 ACS have been slated for adoption by several other major national surveys, including the Current Population Survey, the National Health Institute Survey, and the Survey of Income and Program Participation. ${ }^{5}$ This standardization of survey items emphasizes the importance of understanding the causes and implications of enumerator/respondent errors, as well as of identifying segments of society that may be more susceptible to these problems.

Thus, following our discussion of the tables of descriptive statistics, we will evaluate logit estimations to uncover the role of respondent characteristics upon the likelihood of falsenegative and false-positive events in the reporting of an employment disability. We do this by using a model described in general form by:

$$
y_{i t}=\alpha+\beta X_{i t}+\varepsilon_{i t}
$$

Here, the set of covariates contained in $X_{i t}$ may include: age and its square, gender, categories of educational attainment, race, type of disability (i.e., sensory, physical, mental, or self-care), and an indicator for whether the respondent's record was enumerated (Census 2000) or used Computer Assisted Telephone or Personal Interview (CATI/CAPI) techniques (ACS).

The logits are modeled for working-age (21-64 years) individuals in the Census 2000 and 2000-2005 ACS using two separate base populations: (i) SSI recipients; and (iii) no SSI recipients and no sensory, physical, mental, or self-care disability. The first specification evaluates false-negative responses of SSI recipients to the work limitation measure, where

$$
\begin{gathered}
y_{i t}=0 \text {, if individual } i \text { has an employment disability, } \\
1 \text {, otherwise, }
\end{gathered}
$$

while the second examines false-positive responses by reversing the $0 / 1$ assignment of $y_{i t}$ in equation (2) above.

\section{Results from Descriptive Statistics}

\section{A. Trends}

Table 1 provides disability prevalence rates and the percentage reporting SSI payments from the Census 2000 and the 2000-2005 ACS. It highlights the concerns and subsequent improvements to the ACS. The disability prevalence rate estimate from the Census 2000 (19.0 percent) was much larger than the 2000 ACS estimate (13.7 percent). This difference appears to have been driven by the employment disability (Census 2000, 12.4 percent; 2000 ACS, 7.6 percent) and to a lesser extent the go-outside-home disability (Census 2000, 6.4 percent; 2000 ACS, 4.1 percent). For sensory, physical and mental disabilities, the differences were in the

\footnotetext{
${ }^{5}$ The 2008 ACS disability items exclude the work limitation question and separate the sensory disability into its visual and hearing component parts.
} 
opposite direction (lower in the Census 2000 than in the 2000 ACS). Results from the self-care disability remain consistent across sources. The slight difference in the percentage reporting SSI payments (Census 2000, 1.9 percent; 2000 ACS, 1.8 percent) further suggests the potential for a response/enumerator error in the employment disability item.

To address this issue, the Census Bureau inserted the lead-in stem between the self-care disability and go-outside-home disability items in the 2003 ACS. Table 1 also shows that the disability prevalence rate declines between 2002 (13.8 percent) and 2003 (12.0 percent). This decline appears to be driven by the rephrasing of the questionnaire that impacted the go-outsidehome disability (4.1 percent to 2.9 percent) and employment disability (7.6 percent to 6.9 percent) items. The implication of the latter shift is that working-age individuals were less likely to interpret the question as asking if they were working. ${ }^{6}$ The prevalence rates of the sensory, physical and mental disabilities remain unchanged between 2002 and 2003, while a slight increase in self-care disabilities (1.9 percent to 2.0 percent) is apparent. The percentage reporting SSI payments increases slightly, as well (1.8 percent to 1.9 percent).

For 2003 and 2004, the disability prevalence rate stabilizes at 12.0 percent and 12.1 percent, respectively, and then unexpectedly rises to 12.6 percent in 2005 . This increase is across all six disability sub-categories. Most dramatically, the sensory disability prevalence rate was 2.8 percent during 2000-2004, but rose to 3.0 percent in 2005 . The major change in the ACS was the expansion of the sampling frame to improve local area estimation.

\section{B. Mail-back and Enumerated Samples}

The ACS is conducted using three modes of data collection: mail, telephone, and personal visits. All addresses in the sample are sent a pre-notification letter, the ACS questionnaire package, and a reminder card. If no questionnaire is received, a replacement questionnaire package is sent. A trained, permanent Census Bureau representative attempts to contact non-response addresses by telephone, with a sample of those addresses not responding by mail or by telephone being visited in person. All telephone and in-person responses are recorded on a computer using a computer-assisted survey instrument rather than paper form. According to Stern and Brault (2005), in 2003 the weighted response rate to the mail-back paper questionnaire was about 50 percent. The remaining households were enumerated by telephone or personal visit. In the end, the weighted response rate was 96.7 percent in 2003. In contrast, those who did not mail-back the Census 2000 Long-Form were visited by temporary enumerators to collect the data in person. The response rates to the Census 2000 Long-Form and 2000 ACS mail-back questionnaires were 71 percent and 59 percent, respectively (Stern, 2003).

Table 2 compares the mail-back and enumerated samples of the ACS. In the enumerated sample, the disability prevalence rate estimate from the Census 2000 was 25.1 percent compared to 12.3 for the 2000 ACS estimate. In the mail-back sample, the difference was much smaller16.4 percent in the Census 2000 and 14.7 percent in the 2000 ACS. The difference in the enumerated samples of the Census 2000 and 2000 ACS appears to have been driven by the employment disability (Census 2000, 18.4 percent; 2000 ACS, 5.7 percent) and the go-outsidehome disability (Census 2000, 6.4 percent; 2000 ACS, 2.7 percent). This suggests that the

\footnotetext{
${ }^{6}$ Although not reported within Table 1, we observed a corresponding increase in the employment disability prevalence rates among person ages 65 and over (from 24.1 percent in 2002 to 28.2 percent in 2003). The implication is the same- that individuals were less likely to interpret the question as asking if they were workingbut the impact on the estimate is in the opposite direction, because persons ages 65 and over are less likely to be working and thus previously reported not working.
} 
enumerated sample was responsible for the majority of the difference between the Census 2000 and 2000 ACS, in particular the employment and go-outside disabilities.

With regard to the 2003 ACS revisions, Table 2 shows a substantial reduction of disability prevalence rate in the mail-back between 2002 and 2003 (14.9 percent to 11.4 percent). As expected, the largest changes in the mail-back sample were for the go-outside-home and employment disabilities. For the Census 2000, this suggests the potential for problems in the mail-back sample.

With regard to rise in disability prevalence between 2004 and 2005, it appears to have been entirely within the CATI/CAPI sample. The disability prevalence rate did not change in the mail-back sample (11.4 percent in both 2004 and 2005); this is true for all disability subtypes except the go-outside-home disability, which actually declined. The rise in the CATI/CAPI sample occurred for all six disability sub-types. This suggests that the CATI/CAPI sample or process affected the population statistics for this group of individuals in a manner that is not limited to just the go-outside-home and employment disability items.

\section{Reporting of Employment Disability}

Thus far, our inferences result from comparing patterns in the prevalence rates with what we know about changes in Census Bureau procedures. These changes have reduced inaccurate identification of disability status (i.e., false-positives and -negatives). However, a reduction in prevalence rates may be due to increased false-negatives, decreased false-positives, or reduced true-positives. Using SSI information, we can get a sense of the degree of false-negatives among a certain population; the SSI information is not by itself useful for false-positives.

Table 3 provides employment-disability prevalence rate among working-age individuals reporting the receipt of SSI income in the Census 2000 and the 2000-2005 ACS, by survey mode. When comparing the Census 2000 and 2000 ACS, the employment disability prevalence rate was larger in the 2000 ACS for both the mail-back sample (Census 2000, 48.7 percent; 2000 ACS, 57.4 percent) and the enumerated sample (Census 2000, 46.4 percent; 2000 ACS, 68.2 percent), and it was almost three times as large in the enumerated sample. To further restrict the sample to people who are more likely to have a "true" employment disability, Table 3 also provides the employment disability prevalence rates for people who report receiving SSI and have a self-care disability and one other disability (excluding the go-outside-home disability). When comparing the Census 2000 and 2000 ACS, the employment disability prevalence rate was larger in the 2000 ACS for both the mail-back sample (Census 2000, 58.8 percent; 2000 ACS, 67.6 percent) and the enumerated sample (Census 2000, 63.5 percent; 2000 ACS, 87.7 percent), and it was almost three times as large in the enumerated sample. These findings suggest that the ACS as a whole was an improvement over the Census 2000, particularly in its use of CATI/CAPI for enumeration.

With regard to the implemented changes to the ACS questionnaire between 2002 and 2003, the employment disability prevalence rate among SSI recipients increased in both the mailback and enumerated sample. This occurred to a greater degree in the mail-back sample (from 64.3 percent to 83.4 percent) than in the enumerated sample (from 68.6 percent to 78.5 percent). Regarding SSI recipients who also report a self-care disability and at least one other disability (excluding the go-outside-home disability), while the employment disability prevalence rate increased in both samples, it did so even more in the mail-back sample (from 71.9 percent to 93.8 percent) than in the enumerated sample (from 88.8 percent to 94.1 percent). This suggests 
that the 2003 modifications positively influenced both modes, but particularly the mail-back sample.

Little change in the employment disability prevalence rates between 2004 and 2005 is apparent, in either mode. This suggests that source of the apparent seam may not have been within the population receiving SSI. And recall that the prevalence rates increased between 2004 and 2005 across all types of disability, not just employment definitions, so examining employment disability prevalence rates may not identify the issues.

With regard to false-positives for the employment disability, we examine those who are likely not to report employment disability and evaluate changes and differences across source and mode. Table 4 provides employment disability prevalence rates for those who do not receive SSI income and do not report any of the following: sensory, physical, mental, or selfcare disability. We do not expect the employment disability prevalence rates to be zero, as this would assume that these four items identify all conditions that would cause a person to accurately report an employment disability. However, we are interested in shifts in prevalence rates that are apparent across years and data sources.

As shown in Table 4, the employment disability prevalence rates of this population was substantially different in the enumerated samples of the Census 2000 (15.7 percent) and 2000 ACS (0.8 percent) in comparison with the mail-back sample (Census 2000, 6.2 percent; 2000 ACS, 4.2 percent), which highlights the benefit of the ACS CATI/CAPI process. With regard to the rephrasing of the ACS questionnaire that occurred between 2002 and 2003, the employment disability prevalence rate among SSI recipients increased in both the mail-back and CATI/CAPI enumerated sample, although to a greater degree in the mail-back sample (from 64.3 percent to 83.4 percent) than in the enumerated sample (from 68.6 percent to 78.5 percent). With regard to the change in the ACS questionnaire between 2002 and 2003, the employment disability prevalence rate decreased substantially in the mail-back sample (4.6 percent to 1.3 percent) but only rose slightly in the CATI/CAPI enumerated samples ( 0.7 percent to 0.8 percent).

\section{Logit Analyses}

We turn now to statistical methods that will enable us to evaluate the role of respondent characteristics in false-negative and false-positive reports of an employment disability. As discussed earlier, we limit our sample to those of working-age (21-64 years) in the restrictedaccess versions of the Census 2000 and 2000-2005 ACS. The population is further partitioned using SSI recipiency and a subset of disability measures as a means to derive information regarding the accuracy of responses. The results from the estimated models are discussed below.

\section{A. False-Negatives - SSI Recipients}

This model examines the impact of individual characteristics upon the likelihood that non-workers (i.e., SSI recipients who are younger than 65) provide false-negative responses to the employment disability question, "Because of a physical, mental, or emotional condition lasting 6 months or more, does this person have any difficulty in doing any of the following activities: ... Working at a job or business?” The coefficient estimates from the logit estimation using the sample of all SSI recipients are presented in Table 5, with the corresponding odds 
ratios $^{7}$ in Table 6 . The model attempts to identify the manner in which specific characteristics influence the inaccurate reporting of the absence of an employment disability for disability beneficiaries. Supplemental Security Income recipients of working-age who claim they do not have an employment disability are believed to have answered this questionnaire item with a false-negative response.

Results indicate that female SSI recipients are more likely than their male counterparts to mistakenly report the absence of an employment disability. Curiously, female ACS respondents were on average 15.6 percent more likely to do so than men during 2003-2005, up from an average of 13.0 percent during 2000-2002 and 11.7 percent in the Census 2000. This implies that the rephrasing of the question in the ACS, which repeated the question's stem, actually induced slightly more women who receive disability benefits to indicate that they do not have difficulty working at a job or business.

Relative to those who have not completed high school, more educated individuals receiving SSI were more likely to report an employment disability during 2000-2002. In these years, higher educational attainment for the most part was associated with a reduced likelihood of false-negatives. The redesign of the ACS questionnaire caused college graduates in 2003 and 2004 to be 26.6 percent and 30.1 percent more likely than those without a high school diploma to misreport, respectively. The error could be related to a more literal interpretation of the question; mention of an employment disability may have been omitted since these individuals do not work (i.e., they may have felt that it would not be correct to indicate current difficulty working at a job or business when they are not actively employed).

A similar seam is apparent when examining the responses of non-whites relative to whites: blacks, Asians, and other races demonstrate a significant jump in the likelihood of falsenegative answers to the employment disability question between the 2002 and 2003 ACS. Hispanics compared to non-Hispanics were, on average, more likely to misreport this item. We see that the rephrasing of the disability questions did not greatly impact their tendency toward misclassification (results range from Hispanics being 31.3 percent to 57.6 percent more likely to misreport than non-Hispanics during 2000-2002, and from 35.7 percent to 56.9 percent during 2003-2005).

Also of note is the manner in which the repetition of the stem beginning in 2003 influenced individuals with certain other disabilities to have false-negative responses to the employment disability question. Those with a sensory disability were only at most 14.1 percent more likely than their peers to report false-negatives in the ACS before 2003, while they were between 32.7 percent and 40.2 percent more likely to do so in the years that followed. Falsenegative responses to the employment disability question for those with physical, mental, and self-care disabilities, which were already of lower likelihood relative to other SSI recipients, decreased by 13.2 to 19.2 percentage points after the rephrasing of the question. ${ }^{8}$

We also see the effect of enumerators and CATI/CAPI on the accuracy of the Census 2000 and ACS results relative to those who submitted the mail-back questionnaire. Interestingly, the temporary Census employees who were hired to serve as enumerators influenced the

\footnotetext{
7 Exponentiating the coefficient estimates yields the odds ratio, $\mathrm{e}^{\beta}$. Holding other variables in the model at fixed values, the ratios reveal the odds of having an employment disability for people with the characteristic $\beta$ as compared to those without that characteristic. Subtracting one from the resulting value, $\mathrm{e}^{\beta}-1$, permits interpretation of the odds ratio in terms of percent change.

8 On average, responses to the 2000-2002 and 2003-2005 ACS work limitation questions for those with physical disabilities were -32.7 percent and -47.2 percent as likely to be false-negatives, respectively; mental, -37.3 percent and -50.4 percent; and self-care, -50.4 percent and -69.7 percent.
} 
likelihood of SSI recipients to report that they have no employment disability 1.7 percent more often in the Census 2000 than those who did not interface with a Census employee. As Stern suggests, this is may be due to the page turn in the Census 2000 enumerator survey that separated the employment disability question from the lead statement "because of a physical, mental, or emotional condition does this person have difficulty in doing any of the following activities?" Permanent Census employees who interviewed ACS individuals using CATI/CAPI during 20002002, however, on average reduced the likelihood of false-negatives by 32.3 percent. After the change to the questionnaire, CATI/CAPI respondents were, on average during 2003-2005, 29.2 percent more likely to misreport. Again, the perceived drop in the likelihood of inaccurate responses among enumerated respondents in years after 2002 reveals the strength of the rephrasing of the disability questions in the mail-back survey (i.e., by comparison, the enhancement effects of CATI/CAPI are lessened once the paper version is improved).

\section{B. False-Positives - No SSI Recipients and No Sensory, Physical, Mental, or Self-Care Disability}

In order to examine the likelihood of false-positive responses to the employment disability question in the Census 2000 and 2000-2005 ACS, we construct a sample of workingage people who do not receive SSI income and who do not report a sensory, physical, mental, or self-care disability. This group of individuals is considered unlikely to have an employment disability, although the existence of a physical, mental or emotional condition lasting six months or more resulting in difficulty in working at a job or business cannot be ruled out with certainty. Coefficient estimates from the logit model used to evaluate errors in reporting are in Table 7, with the corresponding odds ratios presented in Table 8. These statistics are highly informative, revealing distinct patterns that demonstrate the impact that the 2003 ACS redesign had on the interpretation of the employment disability item.

We see the remarkable effect of Census enumerators and ACS CATI/CAPI personnel on the likelihood of false-positive reports of having an employment disability (respondents were 1.47 times more likely to mistakenly report this in the Census 2000, compared with being 87.8 percent less likely to do so in the 2000 ACS). The CATI/CAPI findings are consistent until 2003, when people interfacing with this technology are 41.5 percent less likely to inaccurately report an employment disability. With each subsequent year, CATI/CAPI continues to reduce the impact of this type of error, but to a lesser extent. This may reflect the vast improvement of the 2003-2005 mail-in survey questionnaire layout relative to the pre-existing enhancements to item interpretation contributed by enumeration procedures.

Women in this sample were less likely than their male counterparts to cite an employment disability in the Census 2000 (-23.9 percent) and 2000-2002 ACS (averaging -15.8 percent). Beginning in 2003, a shift occurred, with the women being only 3.0 percent less likely to have false-positive reports. In the 2004 and 2005 ACS, women were approximately 6.0 percent more likely to do so.

Erroneous reports of employment disability follow a set pattern in regards to educational attainment: relative to those without a high school degree, more education reduces the likelihood of inaccurate responses by 27.9 percent for those with a high school diploma, 47.1 percent for those with some college, and 74.2 percent for college graduates on average in the 2000-2002 ACS. The likelihood, with respect to those with the least years of schooling, falls even further 
for each education category after the redesign of the ACS in 2003 (reductions of 45.1 percent, 59.7 percent, and 79.3 percent, respectively).

Meanwhile, relative to whites, non-whites have an increased propensity to have falsepositives. In the Census 2000, blacks and Asians (80.0 percent and 78.1 percent more likely than whites, respectively) were approximately as likely to misreport employment disability, whereas Asians were more likely to do so in the 2000-2002 ACS (on average, they were 1.28 times more likely) than blacks (1.14 times more likely). Following the changes to the questionnaire, the tendency reversed (Asians were 31.1 percent more likely, whereas blacks were 73.0 percent more likely to do so). Hispanics were 76.2 percent more likely than non-Hispanics to misreport in the Census 2000, while they were on average 62.7 percent more likely in the 2000-2002 ACS. The rephrasing of the employment disability question resulted in Hispanics being on average 18.1 percent less likely to misreport.

\section{Conclusions}

Our results suggest that the ACS CATI/CAPI enumeration process reduced the measurement error (reduction of false-positives and false-negatives) in response to the employment disability item relative to those who answered the mail-back version of the survey in years prior to 2003. The ACS, when compared to the Census 2000, also exhibits less of a tendency for inaccurate reports. This may be attributed to the use of professional/permanent interview staff in the fielding of the ACS, the use of CAPI/CATI, or the page turn in the Census 2000 enumerator form. The 2003 modification to the ACS questionnaire increased the likelihood of false-negatives in response to the employment disability item in the enumerated sample of SSI recipients relative to the 2000-2002 ACS. This may illustrate the degree to which the improvements to the mail-back version of the ACS questionnaire beginning in 2003 served to reduce the number of both false positive and false negative reports of employment disability as compared to respondents who were interviewed with CATI/CAPI.

The populations under study (partitioned by SSI recipiency and further subset by disability status) have their own characteristic patterns of employment disability misclassification. The qualities of the underlying populations result in unique responses to the 2003 adjustments to the ACS questionnaire, as well. For example, we have uncovered that educational attainment is for the most part associated with a lower likelihood of misreporting the presence or absence of an employment disability. However, the 2003 ACS rephrasing actually raised the likelihood that more educated SSI beneficiaries would cite a lack of employment disability (false-negatives). This seems to support a more literal interpretation of the posed question subsequent to the rewording.

For categories of disability, the repetition of the stem increased the likelihood of falsenegatives amongst disability beneficiaries. Relative to their peers, those with physical, mental, and self-care disabilities were even less likely to misreport beginning in 2003, whereas those with sensory disabilities had a substantially greater tendency to do so. The restatement also may have clarified the employment disability question for Hispanics not receiving SSI benefits and who are without disability. They were less likely than non-Hispanics to erroneously answer this item during 2003-2005.

Work limitation-based questions remain an important way to evaluate U.S. disability policy and therefore employment disability continues to be an essential — but challengingconcept to measure. Using a relatively small amount of information that is external to the work 
limitation response (i.e., SSI receipt and information on other disabilities) suggests that with more advanced enumeration procedures and more explicit question design, false-positives and false-negatives may be minimized. 


\section{References}

Banks, J., Kaptyen, A., Smith, J.P., \& van Soest, A. 2005. "Work Disability is a Pain in the ***, Especially in England, The Netherlands, and the United States," National Bureau of Economic Research, Working Paper \#11558.

Burkhauser, R.V., Butler, J.S., Feng, S., \& Houtenville, A.J. 2004. "Long Term Trends in Earnings Inequality: What the CPS Can Tell Us,” Economic Letters, 82 (2): 295-299.

CESSI. 2003. Federal Statutory Definitions of Disability. Paper prepared for the Interagency Committee on Disability Research. Retrieved May 17, 2006, from http://www.icdr.us/documents/definitions.htm.

Jette, A.M., \& Badley, E. 2000. “Conceptual Issues in the Measurement of Work Disability.” In Nancy Mathiowetz and Gooloo S. Wunderlich (Eds.), Survey Measurement of Work Disability. Washington, D.C.: National Academy Press.

Mashaw, J., \& Reno, V. 1996. Balancing Security and Opportunity: the Challenge of Disability Income Policy. Report of the Disability Policy Panel, National Academy of Social Insurance, Washington, D.C.

Keller-McNulty, S. 2006. Reference: American Community Survey and Disability. (Letter to Dr. Lewis Kincannon, Director, U.S. Census Bureau). Reproduced in AmStat News, June 2006, p. 4.

Nagi, S. 1965. “Some Conceptual Issues in Disability and Rehabilitation,” in Martin B. Sussman ed. Sociology and Rehabilitation. Washington: American Sociological Association.

Nagi, S. 1976. “An Epidemiology of Disability Among Adults in the United States,” Millbank Memorial Fund Quarterly: Health and Society vol. 54 p. 439-467.

Nagi, S. 1991. "Disability Concepts Revisited: Implications to Prevention.” In Disability in America: Toward A National Agenda for Prevention. Edited by A.M. Pope and A.R. Tarlove. Washington: National Academy Press, pp. 309-327.

Stern, S. 2003. “Counting People with Disabilities: How Survey Methodology Influences Estimates in the Census 2000 and the Census 2000 Supplementary Survey.” Census Bureau Working Paper, www.census.gov/acs/www/Downloads/ACS/finalstern.pdf

Stern, S., \& Brault, M. 2005. "Disability Data from the American Community Survey: A Brief Examination of the Effects of a Question Redesign in 2003.” Census Bureau Working Paper, February 28, 2005, www.census.gov/hhes/www/disability/ACS_disability.pdf

U.S. Department of Health and Human Services. 2000. Healthy People 2010. (2 ${ }^{\text {nd }}$ Ed.) Washington: U.S. Government Printing Office. 


\section{Appendix}

The International Classification of Functioning, Disability and Health (ICF) categorization schema uses a similar approach to conceptualize disability. The concepts used include impairment, activity limitation, participation restriction, and disability (see WHO, 2001). A prerequisite to each of these concepts is the presence of a health condition. Examples of health conditions are listed in the International Classification of Diseases, Tenth Edition (ICD10) and they encompass diseases, injuries, health disorders, and other health related conditions. An impairment is defined as a significant deviation or loss in body function or structure. For example, the loss of a limb or vision deterioration may be classified as impairments. In some surveys, impairments are defined as long-lasting health conditions that limit a person's ability to see or hear, limit a person's basic physical movement, or limit a person's mental capabilities.

An activity limitation is defined as the difficulty an individual may have in executing activities. For example, a person who experiences difficulty dressing, bathing or performing other activities of daily living due to a health condition may be classified as having an activity limitation. In some surveys, activity limitations are identified based upon a standard set of activities of daily living questions (ADLs).

A participation restriction is defined as a problem that an individual may experience in involvement in life situations. For example, a working-age person with a health condition may have difficulty participating in employment as a result of the physical environment (e.g., lack of reasonable accommodations) or the social environment (e.g., discrimination). In some surveys, participation restrictions are identified by questions that ask whether the person has a longlasting health condition that limits his or her ability to work, or whether a health condition affects his or her ability to go outside the home to go shopping, attend church, or visit a doctor's office.

In the ICF the term disability describes the presence of an impairment, an activity limitation or a participation restriction. While these concepts may seem to follow a progression - that is, an impairment leading to an activity limitation leading to a participation restriction - this is not necessarily the case. Figure 1 provides a useful summary of the ICF concepts. It is possible that a person may have a participation restriction without an activity limitation or impairment. For example, a person diagnosed as being HIV positive may not have an evident impairment or activity limitation, but may not be able to find employment due to discrimination resulting from his or her health condition. Similarly, a person with a history of mental illness but who no longer has a loss of capacity or an activity limitation may also be unable to find employment due to discrimination resulting from his or her health condition.

Figure 1 illustrates that while there is an overlap across these concepts, it is possible that one of them can occur without a relation to the others. The universe of the ICF is comprised of health conditions as a whole. Disability is the union of impairment, an activity limitation, or participation restrictions. 
Figure 1. Conceptual Framework of Disability Using ICF Concepts

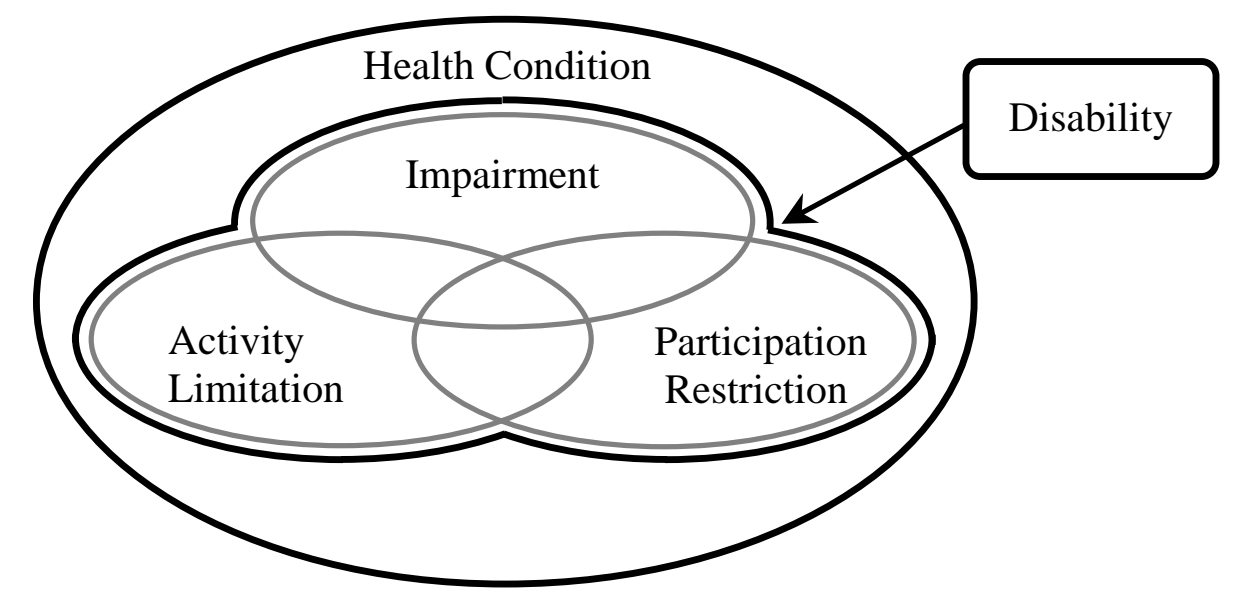

Figure 2. Simplified Conceptual Model of Disability Using Nagi Concepts

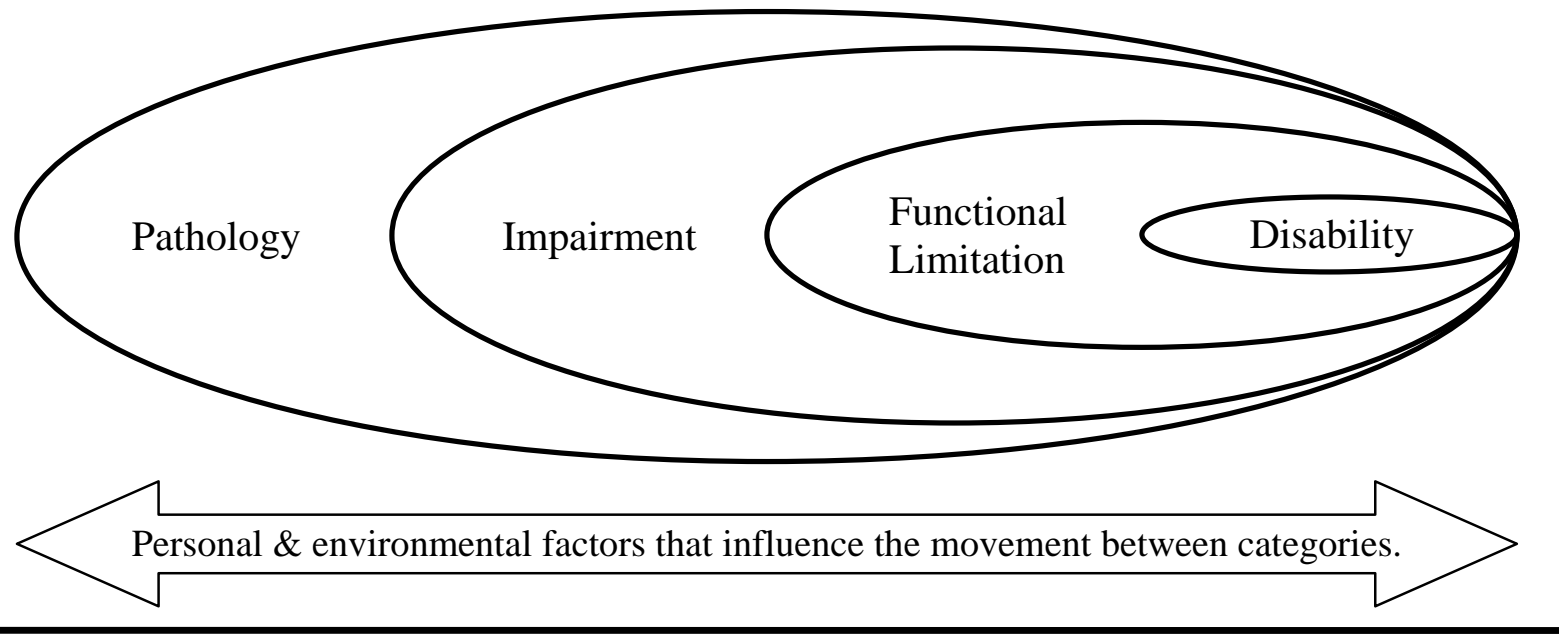


Figure 3. Disability-Related Questions on the Census 2000 Long-Form Mail-Back Questionnaire

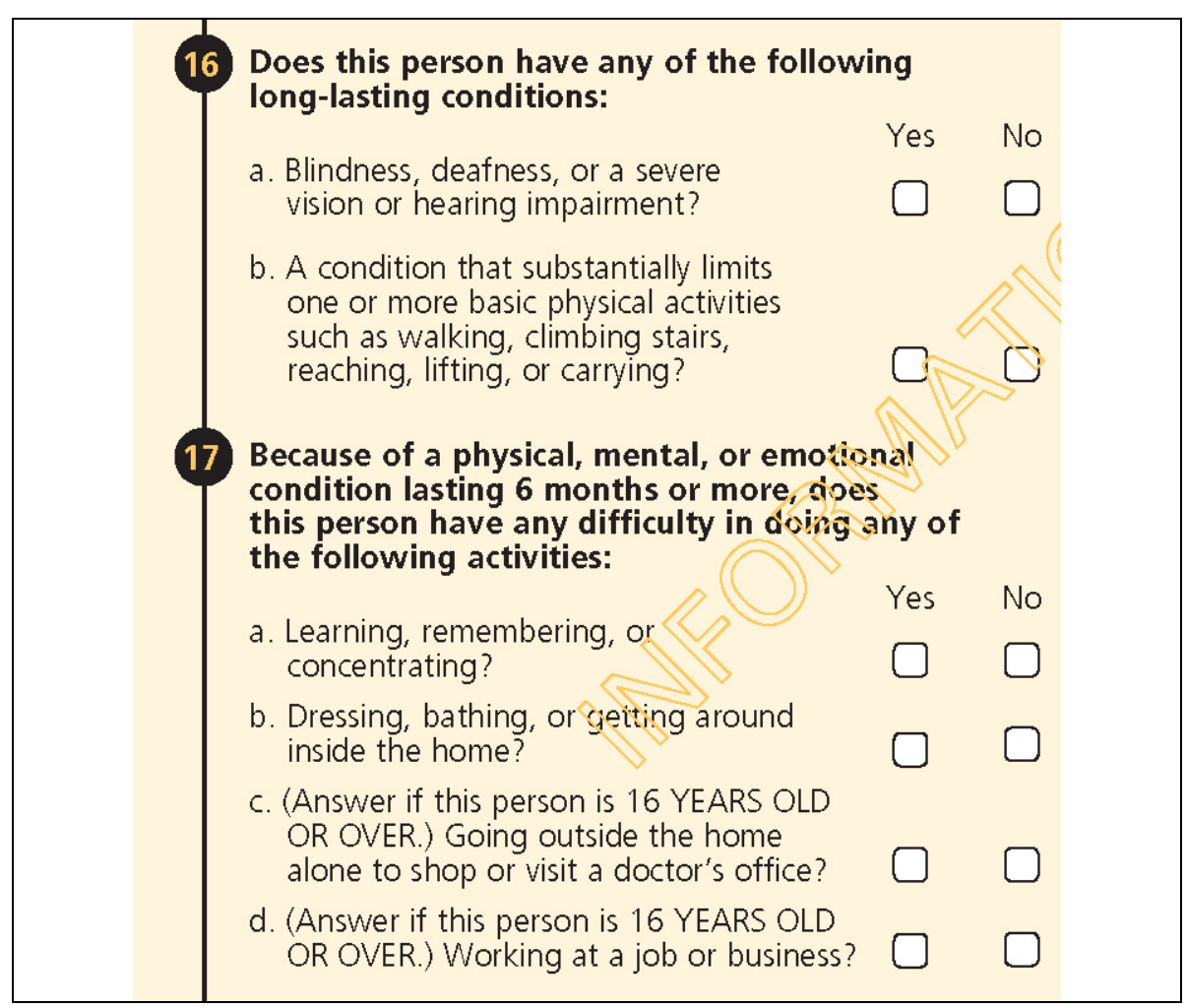

Source: Census Bureau, www.census.gov/dmd/www/pdf/d-61b.pdf. 
Figure 4. Disability-Related Questions on the 2003 ACS Paper Questionnaire

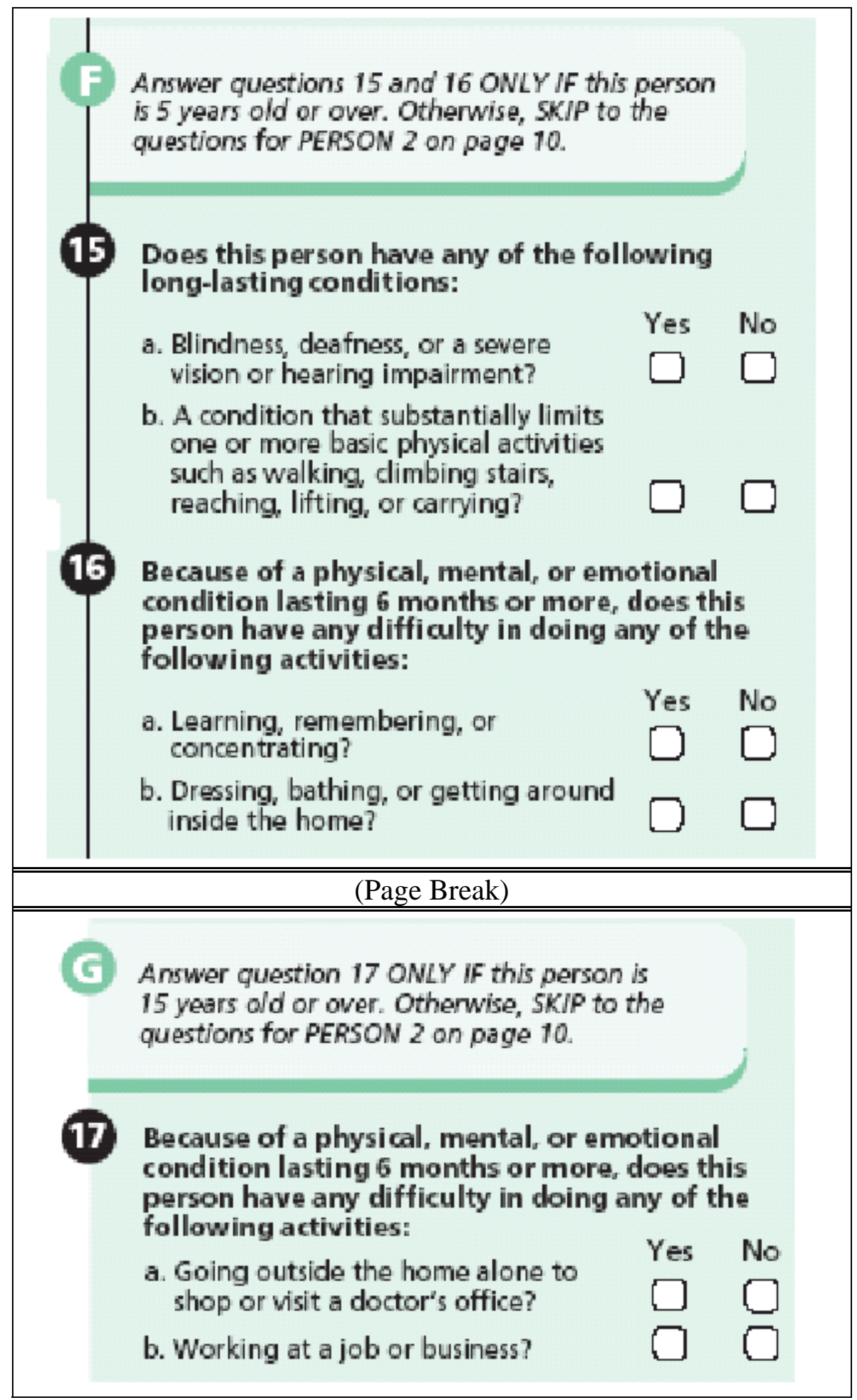

Source: Adapted from Stern and Brault (2005). 
Table 1. Disability Prevalence Rates and Percentage Receiving SSI Income, by Source and Category

\begin{tabular}{|lccccccc|}
\hline \multicolumn{1}{r}{ Category } & Census 2000 & 2000 ACS & 2001 ACS & 2002 ACS & 2003 ACS & 2004 ACS & 2005 ACS \\
\hline Any Disability & 19.0 & 13.7 & 13.6 & 13.8 & 12.0 & 12.1 & 12.6 \\
- Sensory & 2.4 & 2.8 & 2.8 & 2.8 & 2.8 & 2.8 & 3.0 \\
- Physical & 6.7 & 7.1 & 7.3 & 7.5 & 7.5 & 7.6 & 7.8 \\
- Mental & 3.6 & 3.8 & 3.8 & 4.0 & 4.0 & 4.1 & 4.4 \\
- Self-Care & 1.8 & 1.8 & 1.9 & 1.9 & 2.0 & 2.0 & 2.2 \\
- Go-Outside-Home & 6.4 & 4.1 & 4.0 & 4.1 & 2.9 & 3.0 & 3.1 \\
- Employment & 12.4 & 7.6 & 7.4 & 7.6 & 6.9 & 7.0 & 7.3 \\
SSI Receipt & 1.9 & 1.8 & 1.8 & 1.8 & 1.9 & 1.9 & 2.0 \\
\hline
\end{tabular}

Source: Authors' calculations using restricted-access files of Census 2000 and the 2000-2005 American Community Surveys.

Note: All values are weighted. 
Table 2. Disability Prevalence Rates and Percentage Receiving SSI Income, by Source, Category, and Mode

\begin{tabular}{|c|c|c|c|c|c|c|c|}
\hline Category/Mode & $\begin{array}{c}\text { Census } \\
2000\end{array}$ & $\begin{array}{l}2000 \\
\text { ACS }\end{array}$ & $\begin{array}{l}2001 \\
\text { ACS }\end{array}$ & $\begin{array}{l}2002 \\
\text { ACS }\end{array}$ & $\begin{array}{l}2003 \\
\text { ACS } \\
\end{array}$ & $\begin{array}{l}2004 \\
\text { ACS } \\
\end{array}$ & $\begin{array}{l}2005 \\
\text { ACS } \\
\end{array}$ \\
\hline \multicolumn{8}{|l|}{ Any Disability } \\
\hline - Mail-Back & 16.4 & 14.7 & 14.7 & 14.9 & 11.4 & 11.4 & 11.4 \\
\hline - Enumerated & 25.1 & 12.3 & 12.2 & 12.4 & 12.6 & 12.9 & 14.1 \\
\hline \multicolumn{8}{|l|}{ - Sensory } \\
\hline - Mail-Back & 2.3 & 2.4 & 2.4 & 2.4 & 2.2 & 2.2 & 2.2 \\
\hline - Enumerated & 2.7 & 3.4 & 3.3 & 3.3 & 3.4 & 3.5 & 3.9 \\
\hline \multicolumn{8}{|l|}{ - Physical } \\
\hline - Mail-Back & 6.8 & 6.7 & 7.0 & 7.1 & 7.0 & 7.0 & 7.0 \\
\hline - Enumerated & 6.7 & 7.7 & 7.8 & 8.1 & 8.1 & 8.2 & 8.8 \\
\hline \multicolumn{8}{|l|}{ - Mental } \\
\hline - Mail-Back & 3.6 & 3.6 & 3.6 & 3.8 & 3.8 & 3.9 & 3.9 \\
\hline - Enumerated & 3.6 & 4.0 & 4.1 & 4.2 & 4.3 & 4.5 & 5.0 \\
\hline \multicolumn{8}{|l|}{ - Self-Care } \\
\hline - Mail-Back & 1.8 & 1.7 & 1.8 & 1.9 & 2.0 & 2.0 & 2.0 \\
\hline - Enumerated & 1.9 & 1.9 & 1.9 & 1.9 & 2.1 & 2.1 & 2.4 \\
\hline \multicolumn{8}{|l|}{ - Go-Outside-Home } \\
\hline - Mail-Back & 6.4 & 5.2 & 5.1 & 5.2 & 3.0 & 3.0 & 2.9 \\
\hline - Enumerated & 6.4 & 2.7 & 2.6 & 2.7 & 2.9 & 3.0 & 3.4 \\
\hline \multicolumn{8}{|l|}{ - Employment } \\
\hline - Mail-Back & 9.8 & 8.9 & 8.9 & 9.1 & 7.0 & 7.1 & 7.1 \\
\hline - Enumerated & 18.4 & 5.7 & 5.6 & 5.7 & 6.7 & 6.9 & 7.5 \\
\hline \multicolumn{8}{|l|}{ SSI Receipt } \\
\hline - Mail-Back & 1.8 & 1.7 & 1.6 & 1.7 & 1.7 & 1.7 & 1.8 \\
\hline - Enumerated & 2.2 & 2.0 & 2.0 & 2.0 & 2.2 & 2.1 & 2.3 \\
\hline
\end{tabular}

Source: Authors' calculations using restricted-access files of Census 2000 and the 2000-2005 American Community Surveys.

Note: All values are weighted. 
Table 3. Employment-Disability Prevalence Rate among Working-Age Persons Reporting Receipt of SSI Income, by Source, Category, and Mode

\begin{tabular}{|lccccccc|}
\hline \multicolumn{1}{|c}{ Category/Mode } & $\begin{array}{c}\text { Census } \\
\mathbf{2 0 0 0}\end{array}$ & $\mathbf{2 0 0 0}$ ACS & $\mathbf{2 0 0 1}$ ACS & 2002 ACS & 2003 ACS & 2004 ACS & 2005 ACS \\
\hline SSI with Self-Care Disability and & Either Sensory, & Physical or & Mental Disability & & & \\
- Mail-Back & 58.8 & 67.6 & 70.6 & 71.9 & 93.8 & 94.6 & 93.9 \\
- Enumerated & 63.5 & 87.7 & 90.8 & 88.8 & 94.1 & 94.1 & 94.1 \\
SSI & & & & & & & \\
- Mail-Back & 48.7 & 57.4 & 61.1 & 64.3 & 83.4 & 84.3 & 84.0 \\
- Enumerated & 46.4 & 68.2 & 69.7 & 68.6 & 78.5 & 79.3 & 80.5 \\
\hline
\end{tabular}

Source: Authors' calculations using restricted-access files of Census 2000 and the 2000-2005 American Community Surveys.

Note: All values are weighted.

Table 4. Employment-Disability Prevalence Rate among Working-Age Persons Not Reporting Sensory, Physical, Mental or Self-Care Disability, or Receipt of SSI Income, by Source and Mode

\begin{tabular}{|cccccccc|}
\hline Mode & $\begin{array}{c}\text { Census } \\
\mathbf{2 0 0 0}\end{array}$ & 2000 ACS & 2001 ACS & 2002 ACS & 2003 ACS & 2004 ACS & 2005 ACS \\
\hline Mail-Back & 6.2 & 4.8 & 4.6 & 4.6 & 1.3 & 1.2 & 1.3 \\
Enumerated & 15.7 & 0.8 & 0.7 & 0.7 & 0.8 & 0.8 & 1.0 \\
\hline
\end{tabular}

Source: Authors' calculations using restricted-access files of Census 2000 and the 2000-2005 American Community Surveys.

Note: All values are weighted. 
Table 5. Logit Analysis: False-Negatives - SSI Recipients

\begin{tabular}{|c|c|c|c|c|c|c|c|c|c|c|c|c|}
\hline \multirow[b]{2}{*}{ Variables } & \multicolumn{3}{|c|}{ Census 2000} & \multicolumn{3}{|c|}{2000 ACS } & \multicolumn{3}{|c|}{2001 ACS } & \multicolumn{3}{|c|}{2002 ACS } \\
\hline & \multicolumn{2}{|c|}{ Coeff. } & \multirow{2}{*}{$\begin{array}{c}\text { Std. Dev. } \\
0.017\end{array}$} & \multicolumn{2}{|c|}{ Coeff. } & \multirow{2}{*}{$\begin{array}{c}\text { Std. Dev. } \\
0.017\end{array}$} & \multicolumn{2}{|c|}{ Coeff. } & \multirow{2}{*}{$\begin{array}{c}\text { Std. Dev. } \\
0.018\end{array}$} & \multicolumn{2}{|c|}{ Coeff. } & \multirow{2}{*}{$\begin{array}{c}\text { Std. Dev } \\
0.018\end{array}$} \\
\hline Intercept & 0.820 & $*$ & & 1.252 & $*$ & & 1.413 & $*$ & & 0.661 & $*$ & \\
\hline Age & -0.024 & $*$ & 0.001 & -0.049 & $*$ & 0.001 & -0.065 & $*$ & 0.001 & -0.032 & $*$ & 0.001 \\
\hline Age Squared & 0.000 & $*$ & 0.000 & 0.001 & $*$ & 0.000 & 0.001 & $*$ & 0.000 & 0.000 & $*$ & 0.000 \\
\hline Female & 0.110 & $*$ & 0.002 & 0.119 & $*$ & 0.003 & 0.112 & $*$ & 0.003 & 0.134 & $*$ & 0.003 \\
\hline High School Diploma & -0.152 & $*$ & 0.003 & -0.068 & $*$ & 0.003 & -0.074 & $*$ & 0.003 & -0.060 & $*$ & 0.003 \\
\hline Some College & -0.325 & $*$ & 0.003 & -0.147 & $*$ & 0.004 & -0.097 & $*$ & 0.004 & -0.155 & $*$ & 0.004 \\
\hline College Graduate & -0.351 & $*$ & 0.005 & -0.226 & $*$ & 0.006 & -0.087 & $*$ & 0.006 & -0.253 & $*$ & 0.006 \\
\hline Black & 0.399 & $*$ & 0.003 & 0.354 & $*$ & 0.003 & 0.209 & $*$ & 0.003 & 0.171 & $*$ & 0.003 \\
\hline Asian & 0.324 & $*$ & 0.008 & 0.661 & $*$ & 0.008 & 0.202 & $*$ & 0.008 & 0.448 & $*$ & 0.007 \\
\hline Other Race & 0.089 & $*$ & 0.006 & -0.088 & $*$ & 0.006 & 0.039 & $*$ & 0.006 & -0.044 & $*$ & 0.006 \\
\hline Hispanic & 0.273 & $*$ & 0.004 & 0.455 & $*$ & 0.004 & 0.295 & $*$ & 0.005 & 0.278 & $*$ & 0.004 \\
\hline Sensory Disability & 0.086 & $*$ & 0.003 & 0.081 & $*$ & 0.003 & 0.132 & $*$ & 0.003 & 0.047 & $*$ & 0.003 \\
\hline Physical Disability & -0.446 & $*$ & 0.003 & -0.461 & $*$ & 0.003 & -0.310 & $*$ & 0.003 & -0.425 & $*$ & 0.003 \\
\hline Mental Disability & -0.493 & $*$ & 0.002 & -0.511 & $*$ & 0.003 & -0.466 & $*$ & 0.003 & -0.423 & $*$ & 0.003 \\
\hline Self-Care Disability & -0.335 & $*$ & 0.003 & -0.637 & $*$ & 0.003 & -0.821 & $*$ & 0.003 & -0.659 & $*$ & 0.003 \\
\hline Enumerator or CATI/CAPI & 0.017 & $*$ & 0.003 & -0.497 & $*$ & 0.003 & -0.438 & $*$ & 0.003 & -0.250 & $*$ & 0.003 \\
\hline Observations & \multicolumn{3}{|c|}{483,208} & \multicolumn{3}{|c|}{14,349} & \multicolumn{3}{|c|}{14,219} & \multicolumn{3}{|c|}{12,459} \\
\hline & \multicolumn{3}{|c|}{0.64} & \multicolumn{3}{|c|}{0.65} & \multicolumn{3}{|c|}{0.64} & \multicolumn{3}{|c|}{0.62} \\
\hline Log Likelihood & \multicolumn{3}{|c|}{$-2,031,592$} & \multicolumn{3}{|c|}{$-1,795,546$} & \multicolumn{3}{|c|}{$-1,767,023$} & \multicolumn{3}{|c|}{$-1,827,496$} \\
\hline
\end{tabular}

* Coefficient is significant at the 5\% level. 
Table 5 (Continued)

\begin{tabular}{|c|c|c|c|c|c|c|c|c|c|}
\hline \multirow[b]{2}{*}{ Variables } & \multicolumn{3}{|c|}{2003 ACS } & \multicolumn{3}{|c|}{2004 ACS } & \multicolumn{3}{|c|}{2005 ACS } \\
\hline & \multicolumn{2}{|c|}{ Coeff. } & \multirow{2}{*}{$\frac{\text { Std. Dev. }}{0.020}$} & \multicolumn{2}{|c|}{ Coeff. } & \multirow{2}{*}{$\frac{\text { Std. Dev. }}{0.020}$} & \multicolumn{2}{|c|}{ Coeff. } & \multirow{2}{*}{$\frac{\text { Std. Dev. }}{0.020}$} \\
\hline Intercept & 0.786 & $*$ & & 0.964 & $*$ & & 0.261 & $*$ & \\
\hline Age & -0.065 & $*$ & 0.001 & -0.090 & $*$ & 0.001 & -0.046 & $*$ & 0.001 \\
\hline Age Squared & 0.001 & $*$ & 0.000 & 0.001 & $*$ & 0.000 & 0.000 & $*$ & 0.000 \\
\hline Female & 0.149 & $*$ & 0.003 & 0.166 & $*$ & 0.003 & 0.120 & $*$ & 0.003 \\
\hline High School Diploma & -0.035 & $*$ & 0.004 & 0.102 & $*$ & 0.004 & 0.004 & & 0.003 \\
\hline Some College & -0.012 & $*$ & 0.004 & -0.042 & $*$ & 0.004 & -0.062 & $*$ & 0.004 \\
\hline College Graduate & 0.236 & $*$ & 0.007 & 0.267 & $*$ & 0.007 & 0.074 & $*$ & 0.007 \\
\hline Black & 0.353 & $*$ & 0.004 & 0.240 & $*$ & 0.004 & 0.373 & $*$ & 0.003 \\
\hline Asian & 0.778 & $*$ & 0.009 & 0.768 & $*$ & 0.008 & 0.528 & $*$ & 0.009 \\
\hline Other Race & 0.046 & $*$ & 0.006 & -0.037 & $*$ & 0.007 & 0.259 & $*$ & 0.006 \\
\hline Hispanic & 0.322 & $*$ & 0.005 & 0.451 & $*$ & 0.005 & 0.305 & $*$ & 0.005 \\
\hline Sensory Disability & 0.310 & $*$ & 0.004 & 0.283 & $*$ & 0.004 & 0.338 & $*$ & 0.004 \\
\hline Physical Disability & -0.697 & $*$ & 0.003 & -0.619 & $*$ & 0.003 & -0.604 & $*$ & 0.003 \\
\hline Mental Disability & -0.819 & $*$ & 0.003 & -0.577 & $*$ & 0.003 & -0.725 & $*$ & 0.003 \\
\hline Self-Care Disability & -1.218 & $*$ & 0.005 & -1.214 & $*$ & 0.005 & -1.149 & $*$ & 0.005 \\
\hline Enumerator or CATI/CAPI & 0.283 & $*$ & 0.003 & 0.290 & $*$ & 0.003 & 0.194 & $*$ & 0.003 \\
\hline Observations & 14 & 734 & & & 457 & & 49 & 909 & \\
\hline C & & .72 & & & .70 & & & .71 & \\
\hline Log Likelihood & $-1,411$ & 627 & & $-1,403$ & 049 & & $-1,454$ & 287 & \\
\hline
\end{tabular}

* Coefficient is significant at the 5\% level. 
Table 6. Odds Ratios: False-Negatives - SSI Recipients

\begin{tabular}{|lccccccc|}
\hline \multicolumn{1}{|c}{ Variables } & Census & $\mathbf{2 0 0 0}$ & $\mathbf{2 0 0 1}$ & $\mathbf{2 0 0 2}$ & $\mathbf{2 0 0 3}$ & $\mathbf{2 0 0 4}$ & $\mathbf{2 0 0 5}$ \\
Antercept & $\mathbf{2 0 0 0}$ & ACS & ACS & ACS & ACS & ACS & ACS \\
Age & 2.271 & 3.498 & 4.106 & 1.937 & 2.194 & 2.623 & 1.298 \\
Age Squared & 0.976 & 0.952 & 0.937 & 0.969 & 0.938 & 0.914 & 0.956 \\
Female & 1.000 & 1.001 & 1.001 & 1.000 & 1.001 & 1.001 & 1.000 \\
High School Diploma & 1.117 & 1.127 & 1.119 & 1.143 & 1.161 & 1.181 & 1.128 \\
Some College & 0.859 & 0.934 & 0.929 & 0.941 & 0.966 & 1.107 & 1.004 \\
College Graduate & 0.722 & 0.864 & 0.907 & 0.857 & 0.988 & 0.959 & 0.940 \\
Black & 0.704 & 0.798 & 0.916 & 0.777 & 1.266 & 1.305 & 1.076 \\
Asian & 1.490 & 1.425 & 1.232 & 1.187 & 1.423 & 1.271 & 1.452 \\
Other Race & 1.383 & 1.936 & 1.224 & 1.565 & 2.177 & 2.156 & 1.696 \\
Hispanic & 1.094 & 0.916 & 1.040 & 0.957 & 1.047 & 0.964 & 1.295 \\
Sensory Disability & 1.313 & 1.576 & 1.343 & 1.320 & 1.379 & 1.569 & 1.357 \\
Physical Disability & 1.089 & 1.085 & 1.141 & 1.048 & 1.363 & 1.327 & 1.402 \\
Mental Disability & 0.641 & 0.630 & 0.733 & 0.654 & 0.498 & 0.538 & 0.546 \\
Self-Care Disability & 0.611 & 0.600 & 0.627 & 0.655 & 0.441 & 0.562 & 0.484 \\
Enumerator or CATI/CAPI & 0.715 & 0.529 & 0.440 & 0.518 & 0.296 & 0.297 & 0.317 \\
\end{tabular}


Table 7. Logit Analysis: False-Positives - No SSI Recipients and No Sensory, Physical, Mental, or Self-Care Disability

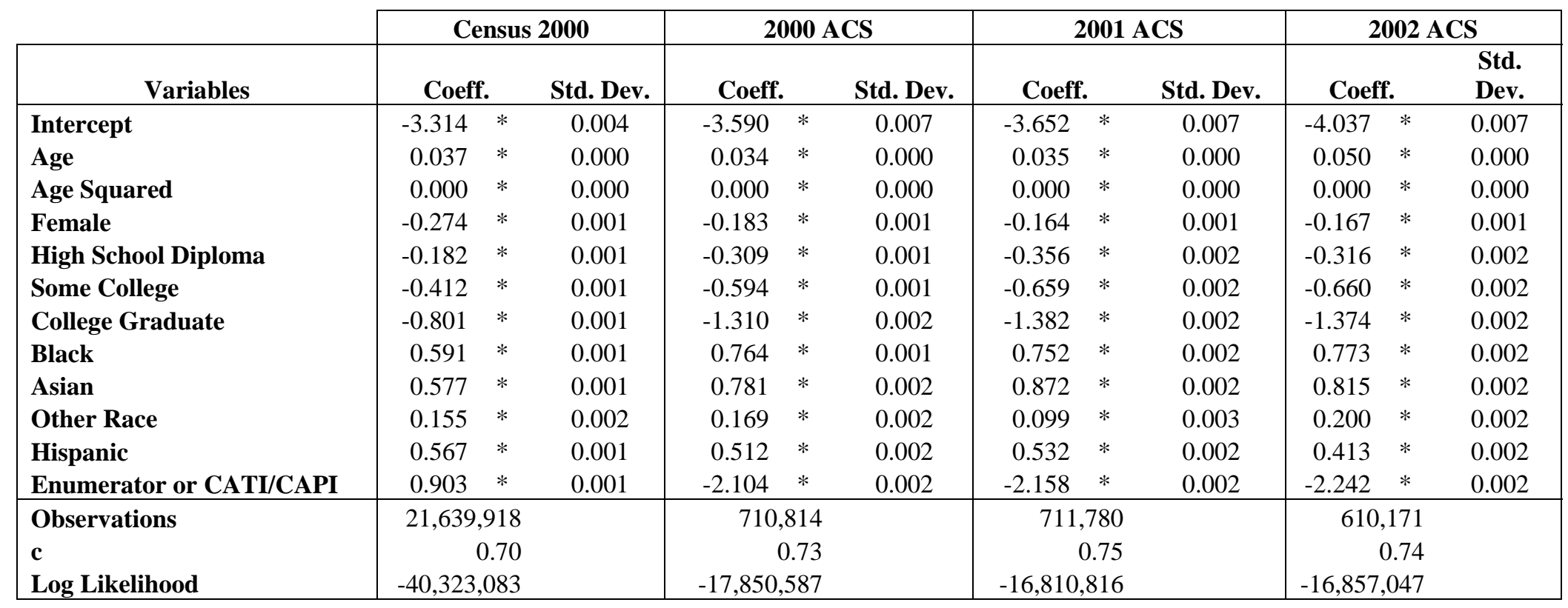

* Coefficient is significant at the $5 \%$ level. 
Table 7 (Continued)

\begin{tabular}{|c|c|c|c|c|c|c|c|c|c|}
\hline \multirow[b]{2}{*}{ Variables } & \multicolumn{3}{|c|}{2003 ACS } & \multicolumn{3}{|c|}{2004 ACS } & \multicolumn{3}{|c|}{2005 ACS } \\
\hline & \multicolumn{2}{|c|}{ Coeff. } & \multirow{2}{*}{$\begin{array}{c}\begin{array}{c}\text { Std. } \\
\text { Dev. }\end{array} \\
0.011\end{array}$} & \multicolumn{2}{|c|}{ Coeff. } & \multirow{2}{*}{$\frac{\text { Std. Dev. }}{0.011}$} & \multicolumn{2}{|c|}{ Coeff. } & \multirow{2}{*}{$\begin{array}{c}\text { Std. } \\
\text { Dev. }\end{array}$} \\
\hline Intercept & -4.334 & $*$ & & -4.311 & $*$ & & -4.127 & $*$ & \\
\hline Age & -0.007 & $*$ & 0.001 & -0.013 & $*$ & 0.001 & -0.018 & $*$ & 0.000 \\
\hline Age Squared & 0.001 & $*$ & 0.000 & 0.001 & $*$ & 0.000 & 0.001 & $*$ & 0.000 \\
\hline Female & -0.031 & $*$ & 0.002 & 0.057 & $*$ & 0.002 & 0.061 & $*$ & 0.002 \\
\hline High School Diploma & -0.595 & $*$ & 0.002 & -0.596 & $*$ & 0.002 & -0.610 & $*$ & 0.002 \\
\hline Some College & -0.870 & $*$ & 0.002 & -0.916 & $*$ & 0.002 & -0.939 & $*$ & 0.002 \\
\hline College Graduate & -1.511 & $*$ & 0.003 & -1.608 & $*$ & 0.003 & -1.604 & $*$ & 0.003 \\
\hline Black & 0.580 & $*$ & 0.002 & 0.543 & $*$ & 0.002 & 0.521 & $*$ & 0.002 \\
\hline Asian & 0.374 & $*$ & 0.004 & 0.221 & $*$ & 0.004 & 0.207 & $*$ & 0.004 \\
\hline Other Race & 0.132 & $*$ & 0.004 & 0.233 & $*$ & 0.004 & 0.119 & $*$ & 0.004 \\
\hline Hispanic & -0.108 & $*$ & 0.003 & -0.291 & $*$ & 0.003 & -0.211 & $*$ & 0.003 \\
\hline Enumerator or CATI/CAPI & -0.536 & $*$ & 0.002 & -0.473 & $*$ & 0.002 & -0.344 & $*$ & 0.002 \\
\hline Observations & \multirow{2}{*}{\multicolumn{3}{|c|}{$\begin{array}{r}677,685 \\
0.70\end{array}$}} & \multicolumn{3}{|c|}{674,072} & \multicolumn{3}{|c|}{$2,218,705$} \\
\hline c & & & & \multicolumn{3}{|c|}{0.70} & \multicolumn{3}{|c|}{0.69} \\
\hline Log Likelihood & \multicolumn{3}{|c|}{$-8,377,348$} & \multicolumn{3}{|c|}{$-8,268,002$} & \multicolumn{3}{|c|}{$-8,856,695$} \\
\hline
\end{tabular}

* Coefficient is significant at the 5\% level. 
Table 8. Odds Ratios: False-Positives - No SSI Recipients and No Sensory, Physical, Mental, or Self-Care Disability

\begin{tabular}{|c|c|c|c|c|c|c|c|}
\hline Variables & $\begin{array}{c}\text { Census } \\
2000\end{array}$ & $\begin{array}{l}2000 \\
\text { ACS }\end{array}$ & $\begin{array}{l}2001 \\
\text { ACS }\end{array}$ & $\begin{array}{l}2002 \\
\text { ACS }\end{array}$ & $\begin{array}{l}2003 \\
\text { ACS }\end{array}$ & $\begin{array}{l}2004 \\
\text { ACS }\end{array}$ & $\begin{array}{l}2005 \\
\text { ACS }\end{array}$ \\
\hline Intercept & 0.036 & 0.028 & 0.026 & 0.018 & 0.013 & 0.013 & 0.016 \\
\hline Age & 1.038 & 1.034 & 1.035 & 1.052 & 0.993 & 0.988 & 0.982 \\
\hline Age Squared & 1.000 & 1.000 & 1.000 & 1.000 & 1.001 & 1.001 & 1.001 \\
\hline Female & 0.761 & 0.833 & 0.848 & 0.846 & 0.970 & 1.059 & 1.063 \\
\hline High School Diploma & 0.834 & 0.734 & 0.700 & 0.729 & 0.552 & 0.551 & 0.544 \\
\hline Some College & 0.663 & 0.552 & 0.517 & 0.517 & 0.419 & 0.400 & 0.391 \\
\hline College Graduate & 0.449 & 0.270 & 0.251 & 0.253 & 0.221 & 0.200 & 0.201 \\
\hline Black & 1.807 & 2.146 & 2.120 & 2.166 & 1.786 & 1.721 & 1.684 \\
\hline Asian & 1.781 & 2.184 & 2.392 & 2.258 & 1.454 & 1.248 & 1.230 \\
\hline Other Race & 1.168 & 1.184 & 1.105 & 1.221 & 1.141 & 1.263 & 1.126 \\
\hline Hispanic & 1.762 & 1.669 & 1.702 & 1.511 & 0.898 & 0.748 & 0.810 \\
\hline Enumerator or CATI/CAPI & 2.468 & 0.122 & 0.116 & 0.106 & 0.585 & 0.623 & 0.709 \\
\hline
\end{tabular}

